\title{
USO PRÁTICO DE MARCADORES MOLECULARES PARA SELEÇÃO ASSISTIDA NO MELHORAMENTO DE UVAS DE MESA APIRÊNICAS ${ }^{1}$
}

\author{
LUÍS FERNANDO REVERS², VANESSA SAWATZKY LAMPE ${ }^{3}$, PAULO RICARDO DIAS DE OLIVEIRA ${ }^{4}$, \\ UMBERTO ALMEIDA CAMARGO 5 , JÚLIO CÉSAR DE LIMA ${ }^{6}$
}

\begin{abstract}
RESUMO - A hipótese mais bem aceita atualmente para explicar a genética complexa da estenoespermocarpia, observada na videira, indica que a expressão deste fenótipo é controlada por três genes recessivos, independentemente herdados e controlados por um gene regulador dominante $(s d I)$. Em estudo anterior, Lahogue et al. (1998) identificaram um marcador RAPD (Random Amplified Polymorphic DNA) ligado ao gene sdI e utilizaram-no para desenvolver um SCAR (Sequence Characterized Amplified Region) co-dominante denominado SCC8, que pode distinguir, em uma progênie, indivíduos com semente como também selecionar indivíduos apirênicos. Neste trabalho, são apresentados resultados da avaliação do potencial de aplicação do marcador molecular SCAR SCC8 para seleção assistida do caráter da apirenia no melhoramento de uvas de mesa sem sementes. A utilização deste marcador na seleção assistida para apirenia em uvas de mesa mostrou-se viável, e as conseqüências da sua utilização no programa de melhoramento da Embrapa Uva e Vinho são discutidas.
\end{abstract}

Termos para indexação: Vitis, marcador molecular, seleção assistida, apirenia.

\section{PRACTICAL USE OF MOLECULAR MARKERS FOR SEEDLESSNESS ASSISTED SELECTION IN GRAPEVINE BREEDING}

\begin{abstract}
The inheritance of seedlessness in grapevine is based on a complex genetic system, where the expression of three independently inherited recessive genes is controlled by a dominant regulator gene ( $s d I)$. In a previous study, Lahogue et al. (1998) identified a random amplified polymorphic DNA marker, tightly linked to the sdI gene and developed a codominant SCAR (Sequence Characterized Amplified Region) marker named SCC8, that allows the distinction of seeded and seedless plants in a segregating progeny. The aim of the present work was to evaluate the usefullness of the SCAR marker SCC8 for assisted selection of the seedlessness character in grape breeding. According to our results, the use of the SCC8 marker is economically viable and the consequences of its use in the grapevine breeding program at Embrapa Uva e Vinho are discussed. Index terms: Vitis, molecular marker, assisted selection, seedlessness.
\end{abstract}

\section{INTRODUÇÃO}

As condições ambientais do trópico brasileiro, em suas diferentes regiões, possibilitam a planificação da produção de uvas ao longo do ano, o que pode garantir oferta permanente de uvas de boa qualidade, com ampla possibilidade de ocupar espaço em períodos de desabastecimento no mercado internacional (abril-junho e novembrodezembro), quando os preços são particularmente atrativos (Leão, 2001). No ano de 2005, a uva ocupou o $2^{\circ}$ lugar entre as frutas brasileiras mais exportadas, apresentando o maior crescimento (171\%) em relação ao ano de 2004 (Safra, 2005). Esse crescimento tem se dado em virtude da expansão da área de cultivo de uvas apirênicas. Todavia, a utilização de cultivares de uva sem sementes importadas, com dificuldades de adaptação, como é o caso de Thompson Seedless, Superior Seedless, Crimson Seedless e outras, cuja produtividade é baixa e inconstante, ainda limitam o crescimento das exportações brasileiras frente à enorme demanda internacional por uvas sem sementes. Portanto, a falta de cultivares apirênicas (uvas sem sementes) adaptadas às condições ambientais do Brasil, além de limitar a capacidade de exportação, afeta a competitividade da uva brasileira no mercado interno, aberto à comercialização de uvas importadas (Protas et al., 2003).

Ao lançar as três primeiras cultivares brasileiras de uva sem semente (BRS Clara, BRS Linda e BRS Morena), a Embrapa Uva e Vinho deu um passo importante para assegurar a competitividade, sustentabilidade e independência tecnológica da viticultura de mesa nas regiões tropicais e subtropicais do Brasil (Camargo et al., 2003a, 2003b, 2003c). No entanto, a busca de novas cultivares com características agronômicas que atendam às demandas da cadeia produtiva da viticultura brasileira, é um desafio constante.

Na videira, a ausência de sementes é resultante de dois processos biologicamente distintos: partenocarpia ou estenoespermocarpia (Pratt, 1971). No processo de estenoespermocarpia, predominantemente selecionado nos programas de melhoramento de uvas de mesa, o desenvolvimento do embrião e do endosperma inicia-se após a fertilização, mas os tecidos do endosperma degeneram prematuramente, levando à produção de frutos contendo traços de sementes não esclerificados. Cronologicamente, a degeneração do endosperma e a conseqüentemente morte do embrião ocorrem de 3 a 6 semanas após a antese, e o embrião atinge, no máximo, estágio globular (Pratt, 1971; Camargo et al., 1999). Apesar de inúmeros esforços dos melhoristas nos últimos 70 anos, a herança da estenoespermocarpia na videira ainda permanece pouco compreendida (revisão em Stout, 1936; Bouquet \& Danglot, 1996). Atualmente, a hipótese mais bem aceita para explicar a genética complexa da estenoespermocarpia foi proposta por Bouquet \& Danglot (1996). Neste estudo, esses autores sugerem que a expressão da característica é controlada por três genes recessivos herdados de maneira independente e controlados por um gene regulador dominante. Lahogue et al. (1998), aplicando a metodologia de BSA (Bulk segregant analysis), identificaram um marcador RAPD ligado ao gene sdI (gene regulador dominante do fenótipo da apirenia) que foi utilizado para o desenvolvimento de um SCAR co-dominante denominado SCC8.

\footnotetext{
${ }^{1}$ (Trabalho 152/2005). Recebido: 20/09/2005. Aceito para publicação: 23/02/2006.

2 Dr., Pesquisador Nível III, Embrapa Uva e Vinho, Área de Biologia Molecular Vegetal, Rua Livramento, 515, CEP 95700-000, Bento Gonçalves-RS. CNPq. Fone (54) 455.8039. E-mail: luis@cnpuv.embrapa.br.

${ }^{3}$ Graduanda em Ciências Biológicas, Universidade do Vale do Rio dos Sinos, Rua Livramento, 515, CEP 95700-000, Bento Gonçalves-RS. Bolsa Embrapa Uva e Vinho. Fone (54) 455.8059. E-mail: vanessa@cnpuv.embrapa.br.

${ }^{4}$ Dr., Pesquisador Nível III, Embrapa Uva e Vinho, Área de Melhoramento Vegetal, Rua Livramento, 515, CEP 95700-000, Bento Gonçalves-RS. CNPq. Fone (54) 455.8036.E-mail: paulo@cnpuv.embrapa.br.

${ }^{5}$ MSc., Pesquisador Nível II, Embrapa Uva e Vinho, Área de Melhoramento Vegetal , Rua Livramento, 515, CEP 95700-000, Bento Gonçalves-RS. CNPq. Fone (54) 455.8037. E-mail: umberto@cnpuv.embrapa.br.

${ }^{6}$ Pós-graduando em Biologia Celular e Molecular, Programa de Pós-graduação em Biologia Celular e Molecular, Universidade Federal do Rio Grande do Sul, Av. Bento Gonçalves, 9500, Prédio 43421, CEP 91509-900, Porto Alegre-RS. Bolsa CNPq. Fone: (51) 3316.6074.
} 
Segundo estes autores, o marcador co-dominante SCC8 pode distinguir, em uma progênie segregante, indivíduos com semente de indivíduos apirênicos.

Neste trabalho, apresentam-se resultados que corroboram a hipótese da herança da apirenia estenoespermocárpica proposta por Bouquet \& Danglot (1996) e que avaliam o potencial da aplicação do marcador molecular SCAR SCC8 para a seleção assistida do caráter da apirenia no programa de melhoramento da Embrapa Uva e Vinho.

\section{MATERIAL E MÉTODOS}

Material Vegetal: os genótipos de videira utilizados neste trabalho são resultantes do cruzamento CNPUV154, entre as cultivares Seyve Villard 12327 (com semente) e CG87746 (apirênica); do cruzamento CNPUV692, entre as cultivares Seyve Villard 12375 (com semente) e Crimson Seedless (apirênica); de seleções apirênicas do programa de melhoramento da Embrapa Uva e Vinho (BRS Morena, BRS Clara, BRS Linda e Seleções 3; 5; 6 e 8) e de cultivares de uva de mesa apirênicas (Canadice, Flame Seedless, Reliance, Ruby Seedless, Muscat Seedless, Autumm Royal, Fantasy, Superior Seedless, Red Seedless, Maroo Seedless, Perlette, Crimson Seedless, Saturn, Centennial Seedless e Thompson Seedless), totalizando 140 plantas (Tabelas 1 e 2). Os critérios de classificação fenotípica descritos por Lahogue et al. (1998) foram utilizados para a definição das categorias fenotípicas de classificação da apirenia (\% matéria seca de sementes e sementes-traço): \%MS $\geq 55 \%$ : classe 1 - semente normal; $\% \mathrm{MS}<55$ e $\geq 45 \%$ : classe 2 - traço de semente grande; \%MS $<45$ e $\geq 35 \%$ : classe 3 - traço de semente perceptível; $\%$ MS $<35 \%$ : classe 4 - ausência de semente).

Extração de DNA: amostras de folhas expandidas jovens foram coletadas durante a estação de crescimento e armazenadas a $-20^{\circ} \mathrm{C}$ para posterior extração de DNA, utilizando-se do método descrito por Lefort \& Douglas (1999), com modificações no tampão de extração (50mM Tris $\mathrm{HCl}$ pH 8,0; $20 \mathrm{mM}$ EDTA pH 8,0; 1,1M NaCl; 0,4M LiCl; 1\% CTAB; 2\% PVP40 e 0,5\% Tween 20).

Preparo da PCR: 9 ng de DNA total, $250 \mu \mathrm{M}$ dNTPs (2'deoxinucleosideos 5'-trifosfatos - Invitrogen), DMSO (Biosolv Ltd Holanda) 5\%, 10pMoles de cada iniciador (descritos por Lahogue et al., 1998 - SCC8F 5'GGTGTCAAGTTGGAAGATGG3' e SCC8R 5'TATGCCAAA-AACATCCCC3'; sintetizados por Alpha DNA Quèbec, Canadá), 0,5U de Tth DNA polimerase (Biotools - Espanha) e tampão na concentração indicada pelo fabricante. O volume final da reação $(20 \mu \mathrm{l})$ foi ajustado com água ultrapura. O programa utilizado no termociclador foi: $94^{\circ} \mathrm{C}$ por 4 min, 35 ciclos de amplificação $\left(94^{\circ} \mathrm{C}\right.$ por 1 min, $60^{\circ} \mathrm{C}$ por 1 min e $72^{\circ} \mathrm{C}$ por $1 \mathrm{~min}$ ) e extensão final a $72^{\circ} \mathrm{C}$ por 6 min. Indivíduos que não apresentaram produto de amplificação na reação com SCC8F e SCC8R, foram reavaliados utilizando-se, pelo menos, de outras duas amostras de DNA total independentes para confirmar a ausência do marcador no lócus SCC8.

Digestão do produto de amplificação: o produto de amplificação da reação do lócus SCC8 (1011pb) foi digerido em uma reação com volume final de $15 \mu$ l, utilizando-se $7 \mu \mathrm{l}$ da reação de PCR e 2,5 U da endonuclease de restrição Bgl II (MBI Fermentas - Lituânia) durante $7 \mathrm{~h}$ a $37^{\circ} \mathrm{C}$.

Eletroforese e fotodocumentação: os produtos da amplificação foram resolvidos em gel de agarose (GIBCO BRL - New York) 1,5 ou 2\%, contendo brometo de etídio $(0,5 \mathrm{ìg} / \mathrm{ml})$ e fotodocumentados com auxílio do sistema Eagle Eye II - Still Video System (Stratagene).

Comprimento dos fragmentos: o tamanho dos fragmentos (número de pares de base $-\mathrm{pb}$ ) resultantes das reações de PCR e digestão foram estimados utilizando-se do software DNASIZE (Raghava, 1994).

TABELA 1 - Classificação fenotípica e segregação genotípica dos indivíduos da população CNPUV692. C. S.(Crimson Seedless) e SV (Seyve Villard) 12375 representam os genitores do cruzamento CNPUV692; \%MS= porcentagem de matéria seca; $\mathrm{CF}=$ classe fenotípica e nd= valor não determinado.

\begin{tabular}{|c|c|c|c|c|c|c|c|c|c|c|c|}
\hline Indivíduo & \%M.S. & $\mathrm{CF}$ & Genótipos & Indivíduo & \%M.S. & $\mathrm{CF}$ & Genótipos & Indivíduo & \%M.S. & $\mathrm{CF}$ & Genótipos \\
\hline C. S. & $<35,00$ & 4 & $\mathrm{SCC} 8 / 0$ & 4 & nd & nd & $\mathrm{SCC} 8 / \operatorname{scc} 8$ & 189 & 67,33 & 1 & $\operatorname{scc} 8 / 0$ \\
\hline SV 12375 & $>55,00$ & 1 & $\operatorname{scc} 8 / 0$ & 44 & 44,39 & 3 & $\mathrm{SCC} 8 / \operatorname{scc} 8$ & 204 & 62,85 & 1 & $\operatorname{scc} 8 / 0$ \\
\hline 13 & 45,85 & 2 & $\mathrm{SCC} 8 / 0$ & 46 & 54,71 & 2 & $\mathrm{SCC} 8 / \mathrm{scc} 8$ & 213 & 66,51 & 1 & $\operatorname{scc} 8 / 0$ \\
\hline 23 & nd & nd & $\mathrm{SCC} 8 / 0$ & 69 & 46,45 & 2 & $\mathrm{SCC} 8 / \operatorname{scc} 8$ & 270 & 67,10 & 1 & $\operatorname{scc} 8 / 0$ \\
\hline 30 & nd & nd & $\mathrm{SCC} 8 / 0$ & 76 & 66,74 & 1 & $\mathrm{SCC} 8 / \operatorname{scc} 8$ & 291 & 66,19 & 1 & $\operatorname{scc} 8 / 0$ \\
\hline 62 & 66,10 & 1 & $\mathrm{SCC} 8 / 0$ & 143 & nd & nd & $\mathrm{SCC} 8 / \operatorname{scc} 8$ & 329 & 67,17 & 1 & $\operatorname{scc} 8 / 0$ \\
\hline 64 & nd & nd & $\mathrm{SCC} 8 / 0$ & 145 & nd & nd & $\mathrm{SCC} 8 / \operatorname{scc} 8$ & 349 & nd & nd & $\operatorname{scc} 8 / 0$ \\
\hline 85 & 46,35 & 2 & $\mathrm{SCC} 8 / 0$ & 147 & 51,06 & 2 & $\mathrm{SCC} 8 / \operatorname{scc} 8$ & 389 & 71,57 & 1 & $\operatorname{scc} 8 / 0$ \\
\hline 88 & nd & nd & $\mathrm{SCC} 8 / 0$ & 157 & 45,71 & 2 & $\mathrm{SCC} 8 / \operatorname{scc} 8$ & 5 & 66,82 & 1 & $0 / 0$ \\
\hline 107 & nd & nd & $\mathrm{SCC} 8 / 0$ & 162 & 65,30 & 1 & $\mathrm{SCC} 8 / \operatorname{scc} 8$ & 24 & 68,82 & 1 & $0 / 0$ \\
\hline 141 & 45,87 & 2 & $\mathrm{SCC} 8 / 0$ & 170 & 48,22 & 2 & $\mathrm{SCC} 8 / \operatorname{scc} 8$ & 60 & 70,52 & 1 & $0 / 0$ \\
\hline 163 & 40,70 & 3 & $\mathrm{SCC} 8 / 0$ & 200 & 52,27 & 2 & $\mathrm{SCC} 8 / \mathrm{scc} 8$ & 80 & nd & nd & $0 / 0$ \\
\hline 164 & nd & nd & $\mathrm{SCC} 8 / 0$ & 206 & nd & nd & SCC $8 / \operatorname{scc} 8$ & 96 & 64,91 & 1 & $0 / 0$ \\
\hline 187 & 59,48 & 1 & $\mathrm{SCC} 8 / 0$ & 287 & 46,45 & 2 & $\mathrm{SCC} 8 / \mathrm{scc} 8$ & 121 & 71,05 & 1 & $0 / 0$ \\
\hline 199 & nd & nd & $\mathrm{SCC} 8 / 0$ & 304 & 52,73 & 2 & $\mathrm{SCC} 8 / \operatorname{scc} 8$ & 129 & nd & nd & $0 / 0$ \\
\hline 203 & nd & nd & $\mathrm{SCC} 8 / 0$ & 305 & 50,32 & 2 & $\mathrm{SCC} 8 / \operatorname{scc} 8$ & 130 & 68,22 & 1 & $0 / 0$ \\
\hline 209 & 46,93 & 2 & $\mathrm{SCC} 8 / 0$ & 307 & 62,45 & 1 & $\mathrm{SCC} 8 / \operatorname{scc} 8$ & 142 & nd & nd & $0 / 0$ \\
\hline 218 & 69,99 & 1 & $\mathrm{SCC} 8 / 0$ & 335 & 46,88 & 2 & $\mathrm{SCC} 8 / \mathrm{scc} 8$ & 230 & 48,23 & 2 & $0 / 0$ \\
\hline 220 & nd & nd & $\mathrm{SCC} 8 / 0$ & 348 & 44,13 & 3 & $\mathrm{SCC} 8 / \operatorname{scc} 8$ & 244 & 64,03 & 1 & $0 / 0$ \\
\hline 221 & nd & nd & $\mathrm{SCC} 8 / 0$ & 354 & 45,26 & 2 & $\mathrm{SCC} 8 / \mathrm{scc} 8$ & 245 & 68,05 & 1 & $0 / 0$ \\
\hline 224 & 77,69 & 1 & $\mathrm{SCC} 8 / 0$ & 360 & nd & nd & SCC $8 / \operatorname{scc} 8$ & 250 & nd & nd & $0 / 0$ \\
\hline 228 & nd & nd & $\mathrm{SCC} 8 / 0$ & 362 & 47,03 & 2 & $\mathrm{SCC} 8 / \operatorname{scc} 8$ & 282 & 77,12 & 1 & $0 / 0$ \\
\hline 229 & 64,68 & 1 & $\mathrm{SCC} 8 / 0$ & 363 & 53,51 & 2 & $\mathrm{SCC} 8 / \operatorname{scc} 8$ & 300 & 69,56 & 1 & $0 / 0$ \\
\hline 259 & 49,76 & 2 & $\mathrm{SCC} 8 / 0$ & 397 & nd & nd & $\mathrm{SCC} 8 / \mathrm{scc} 8$ & 310 & 69,58 & 1 & $0 / 0$ \\
\hline 280 & 46,95 & 2 & $\mathrm{SCC} 8 / 0$ & 2 & nd & nd & $\operatorname{scc} 8 / 0$ & 324 & 67,09 & 1 & $0 / 0$ \\
\hline 301 & 44,80 & 3 & $\mathrm{SCC} 8 / 0$ & 43 & nd & nd & $\operatorname{scc} 8 / 0$ & 350 & nd & nd & $0 / 0$ \\
\hline 303 & 45,70 & 2 & $\mathrm{SCC} 8 / 0$ & 98 & 72,67 & 1 & $\operatorname{scc} 8 / 0$ & 357 & nd & nd & $0 / 0$ \\
\hline 325 & 49,14 & 2 & $\mathrm{SCC} 8 / 0$ & 100 & 64,70 & 1 & $\operatorname{scc} 8 / 0$ & 358 & nd & nd & $0 / 0$ \\
\hline 336 & 47,95 & 2 & $\mathrm{SCC} 8 / 0$ & 102 & 60,52 & 1 & $\operatorname{scc} 8 / 0$ & 367 & 65,81 & 1 & $0 / 0$ \\
\hline 366 & 49,39 & 2 & $\mathrm{SCC} 8 / 0$ & 114 & nd & nd & $\operatorname{scc} 8 / 0$ & 375 & 64,46 & 1 & $0 / 0$ \\
\hline 374 & 47,18 & 2 & $\mathrm{SCC} 8 / 0$ & 125 & 66,77 & 1 & $\operatorname{scc} 8 / 0$ & 381 & 71,16 & 1 & $0 / 0$ \\
\hline 1 & 63,07 & 1 & SCC $8 / \operatorname{scc} 8$ & 178 & nd & nd & $\operatorname{scc} 8 / 0$ & & & & \\
\hline
\end{tabular}


TABELA 2 - Classificação fenotípica e genotípica de grupos de indivíduos apirênicos (GA) e com semente (GS) da população CNPUV154르 de cultivares de uva de mesa apirênicas e de seleções apirênicas ${ }^{\mathrm{b}}$ \% \%MS= porcentagem de matéria seca; $\mathrm{CF}=$ classe fenotípica e nd= valor não determinado.

\begin{tabular}{|c|c|c|c|c|c|c|c|}
\hline Indivíduo $^{a}$ & \%M.S. & $\mathrm{CF}$ & Genótipos & Indivíduo $^{b}$ & \%M.S. & $\mathrm{CF}$ & Genótipos \\
\hline CG 87746 & $<35,00$ & 4 & $\mathrm{SCC} 8 / 0$ & Flame Sds. & $<35,00$ & 4 & $\mathrm{SCC} 8 / ?$ \\
\hline SV 12327 & $>55,00$ & 1 & $\operatorname{scc} 8 / 0$ & Reliance & $<35,00$ & 4 & $\mathrm{SCC} 8 / ?$ \\
\hline GA20 & 31,45 & 4 & $\mathrm{SCC} 8 / \mathrm{scc} 8$ & Ruby Sds. & $<35,00$ & 4 & $\mathrm{SCC} 8 / ?$ \\
\hline GA24 & 28,12 & 4 & $\mathrm{SCC} 8 / \mathrm{scc} 8$ & Autumm Royal & $<35,00$ & 4 & $\mathrm{SCC} 8 / ?$ \\
\hline GA34 & 32,29 & 4 & $\mathrm{SCC} 8 / \mathrm{scc} 8$ & Fantasy & $<35,00$ & 4 & $\mathrm{SCC} 8 / ?$ \\
\hline GA43 & 29,60 & 4 & $\mathrm{SCC} 8 / \operatorname{scc} 8$ & Crimson Sds. & $<35,00$ & 4 & $\mathrm{SCC} 8 / ?$ \\
\hline GA56 & 30,39 & 4 & $\mathrm{SCC} 8 / \mathrm{scc} 8$ & Saturn & $<35,00$ & 4 & $\mathrm{SCC} 8 / ?$ \\
\hline GA72 & 0,00 & 4 & $\mathrm{SCC} 8 / \mathrm{scc} 8$ & Centennial Seedless & $<35,00$ & 4 & $\mathrm{SCC} 8 / ?$ \\
\hline GA80 & 32,03 & 4 & $\mathrm{SCC} 8 / \mathrm{scc} 8$ & Thompson Sds. & $<35,00$ & 4 & $\mathrm{SCC} 8 / ?$ \\
\hline GA145 & 31,57 & 4 & $\mathrm{SCC} 8 / \operatorname{scc} 8$ & Red Sds & $<35,00$ & 4 & $\mathrm{SCC} 8 / ?$ \\
\hline GA160 & 27,95 & 4 & $\mathrm{SCC} 8 / \mathrm{scc} 8$ & Canadice & $<35,00$ & 4 & $\mathrm{SCC} 8 / \mathrm{scc} 8$ \\
\hline GA27 & 27,10 & 4 & $\operatorname{Scc} 8 / 0$ & Muscat Sds. & $<35,00$ & 4 & $\mathrm{SCC} 8 / \sec 8$ \\
\hline GA22 & 32,28 & 4 & nd & Superior Seedless & $<35,00$ & 4 & $\mathrm{SCC} 8 / \operatorname{scc} 8$ \\
\hline GS19 & 60,70 & 1 & $\operatorname{scc} 8 / 0$ & Maroo Seedless & $<35,00$ & 4 & $\mathrm{SCC} 8 / \sec 8$ \\
\hline GS49 & 61,69 & 1 & $\operatorname{scc} 8 / 0$ & Perlette & $<35,00$ & 4 & $\mathrm{SCC} 8 / \mathrm{scc} 8$ \\
\hline GS69 & 57,95 & 1 & $\operatorname{scc} 8 / 0$ & BRS Morena & $<35,00$ & 4 & $\mathrm{SCC} 8 / ?$ \\
\hline GS94 & 60,28 & 1 & $\operatorname{scc} 8 / 0$ & BRS Clara & $<35,00$ & 4 & $\mathrm{SCC} 8 / ?$ \\
\hline GS112 & 64,20 & 1 & $\operatorname{scc} 8 / 0$ & Seleção 3 & $<35,00$ & 4 & $\mathrm{SCC} 8 / ?$ \\
\hline GS134 & 59,30 & 1 & $\operatorname{scc} 8 / 0$ & Seleção 5 & $<35,00$ & 4 & $\mathrm{SCC} 8 / ?$ \\
\hline GS149 & 57,02 & 1 & $\operatorname{scc} 8 / 0$ & Seleção 6 & $<35,00$ & 4 & $\mathrm{SCC} 8 / ?$ \\
\hline GS48 & 57,73 & 1 & $\mathrm{SCC} 8 / \mathrm{scc} 8$ & BRS Linda & $<35,00$ & 4 & $\mathrm{SCC} 8 / ?$ \\
\hline GS114 & 56,95 & 1 & $\mathrm{SCC} 8 / \mathrm{scc} 8$ & Seleção 8 & $<35,00$ & 4 & $\mathrm{SCC} 8 / ?$ \\
\hline
\end{tabular}

? representa SCC8/SCC8 ou SCC8/0.

Análise estatística: o marcador SCAR SCC8 foi avaliado para presença (1) ou ausência (0) em todo o material vegetal. Na avaliação da segregação fenotípica para apirenia, as classes 2; 3 e 4 foram consideradas apirênicas, conforme sugerido por Lahogue et al. (1998). Desvios entre as segregações observadas e esperadas para o lócus SCC8 foram testadas pelo teste $\chi^{2}$. Análise de correlação (r) foi utilizada para avaliar a associação entre SCC8 e apirenia.

\section{RESULTADOS E DISCUSSÃO}

A característica co-dominante do marcador SCC8 permitiu a diagnose de 3 alelos no lócus SCC8 (SCC8: 1011pb; scc8: 669pb+342pb após digestão com $\mathrm{Bgl}$ II e 0 : alelo nulo - não-amplificação) (Figura 1 e Tabela 1) e 4 genótipos segregantes (SCC8/0; SCC8/scc8; scc8/0 e 0/ 0 ), indicando que ambos os genitores do cruzamento CNPUV692 (Crimson Seedless e Seyve Villard 12375) são heterozigotos para o lócus SCC8. O teste de independência $\chi^{2}$ mostrou que a segregação genotípica observada para o lócus SCC8 na população CNPUV692 não desvia significativamente da segregação esperada 1:1:1:1 $\left(\chi^{2}=3,53 ; p=0,05\right)$. A análise de correlação entre as classes fenotípicas observadas e a presença do alelo SCC8 confirmou a associação entre esse alelo e a ausência de sementes $\left(r_{\text {calc }}=0,66 ; p=0,01\right)$ (Figura 2), confirmando os relatos de Lahogue et al. (1998) e Adam-Blondon et al. (2001). A classificação fenotípica para apirenia, adotando-se o percentual médio de matéria seca das sementes, também revela que a cultivar Crimson Seedless não é um bom genótipo doador de apirenia, pois além de ser heterozigota para o lócus SCC8 (SCC8/0) (Figura 1), nenhum indivíduo classe 4 (\%MS <35\%) foi identificado na população CNPUV692 (Tabela $1)$. Adicionalmente, o teste de independência $\chi^{2}$ mostrou que a distribuição fenotípica não desviou da segregação esperada de 1:1 (apirenia:pirenia; $\chi_{\text {calc }}^{2}=0,38 ; p=0,005$ ) no lócus SCC8 na população CNPUV692, sustentando a hipótese proposta por Bouquet \& Danglot (1996) para a herança da estenoespermocarpia na videira. Para ampliar o espectro do estudo e avaliar se a mesma associação entre a apirenia e a presença de SCC8 ocorre em outras populações, o mesmo procedimento foi aplicado para avaliar híbridos com e sem semente resultantes do cruzamento CNPUV154, seleções apirênicas e cultivares de uva sem sementes já utilizadas comercialmente (Tabela 2). Após a diagnose dos alelos, observou-se que, entre os híbridos da população CNPUV154, a análise de correlação indicou associação entre a presença de SCC8 e a ausência de sementes ( $\left.\mathrm{r}_{\text {calc }}=0,74 ; \mathrm{p}=0,01\right)$. Entretanto, observam-se, no grupo de plantas com semente da população CNPUV154, dois indivíduos que podem representar recombinantes (GS48 e GS114), pois posuem o alelo SCC8 e apresentam semente normal. Nos estudos preliminares desenvolvidos por Lahogue et al. (1998) e Adam-Blondon et al. (2001), a distância estimada entre o gene sdl e o marcador SCC8 foi de $0,7 \mathrm{cM}$ e 4,0 cM, respectivamente. Isto per se pode explicar a ocorrência de recombinantes na população CNPUV154. Nos demais genótipos apirênicos, incluindo-se cultivares e seleções avançadas do programa de melhoramento da Embrapa Uva e Vinho, a presença de SCC8 ocorreu em todos os casos, indicando o potencial de distinção fenotípica deste marcador (Figura 3). Esta observação reforça o caráter de inespecificidade populacional do marcador SCC8 sugerido por Lahogue et al. (1998).

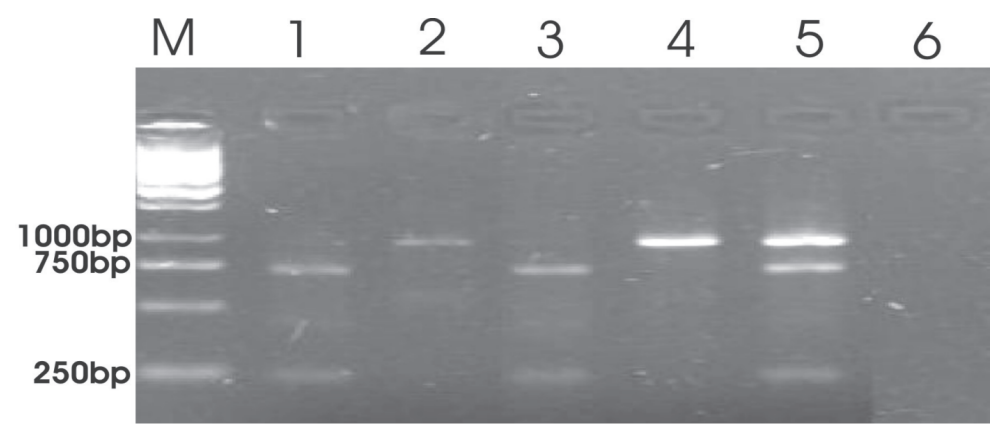

FIGURA 1 - Possíveis genótipos resultantes no lócus SCC8 após digestão com $\mathrm{Bgl}$ II. $\mathrm{M}=$ marcador $1 \mathrm{~Kb}, 1$ e 2= genitores do cruzamento CNPUV692 (Seyve Villard 12375 e Crimson Seedless, respectivamente); 3; 4; 5 e $6=$ possíveis genótipos segregantes. 


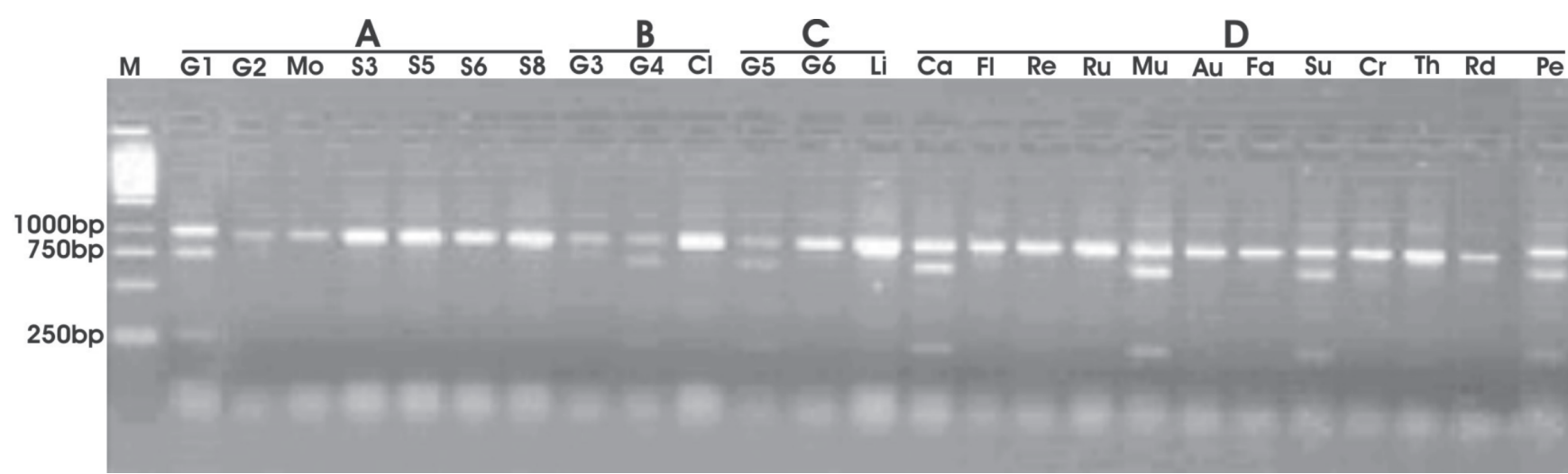

FIGURA 3 - Genótipos de cultivares sem sementes e seleções desenvolvidas pela Embrapa Uva e Vinho. M= marcador 1Kb. A: G1 (Maroo Seedless) e G2 (Centennial Seedless), genitores de Mo (BRS Morena), S3 (Seleção 3), S5 (Seleção 5), S6 (Seleção 6) e S8 (Seleção 8). B: G3 (CNPUV154-147) e G4 (Centennial Seedless), geneitores de Cl (BRS Clara). C: G5 (CNPUV154-90) e G6 (Saturn), genitores de Li (BRS Linda). D: Ca (Canadice); Fl (Flame Seedless); Re (Reliance); Ru (Ruby Seedless); Mu (Muscat Seedless); Au (Autumm Royal); Fa (Fantasy); Su (Superior Seedless); Cr (Crimson Seedless); Th (Thompson Seedless); Re (Red Seedless) e Pe (Perlette).

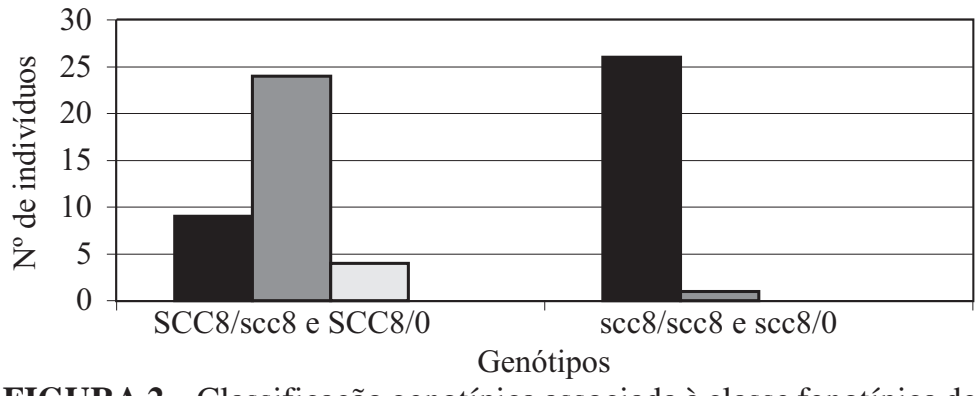

FIGURA 2 - Classificação genotípica associada à classe fenotípica de acordo com o percentual médio de matéria seca [\%MS] de sementes na população CNPUV692. Coluna lilás= Classe 1 (\%MS $\geq 55 \%$ ), coluna bordô= Classe 2 (\%MS $<55$ e $\geq 45 \%$ ); coluna amarela= Classe 3 (\%MS $<45$ e $\geq 35 \%$ ). *Correlação positiva entre genótipos e classes fenotípicas ( $\left.\mathrm{r}_{\text {calc }}=0,66 ; \mathrm{p}=0,01\right)$.

Com essa metodologia, o custo total da reação, utilizando-se do SCAR SCC8, foi de aproximadamente R \$ 4,35 por planta. Comparandose a estimativa de custo da seleção assistida com a do melhoramento genético convencional, estimada em R $\$$ 7,50 por planta (correspondendo somente à instalação e manutenção de campos de seleção de híbridos), a utilização do marcador SCC8 representa uma alternativa viável não somente para seleção precoce de genótipos apirênicos, mas também para a economia de insumos, visto que os custos poderão ser sensivelmente reduzidos ao evitar-se levar ao campo plantas com sementes, que serão avaliadas, no sistema convencional, somente após o primeiro ano de produção.

\section{CONCLUSÃO}

A utilização do marcador molecular SCC8 para seleção assistida da ausência de sementes na videira e na avaliação da herança da estenoespermocarpia foi testada em duas populações segregantes do programa de melhoramento da Embrapa Uva e Vinho (CNPUV692 e CNPUV154), em seleções avançadas e em cultivares de uva sem sementes já utilizadas comercialmente. Os resultados obtidos confirmaram que o marcador SCC8 parece estar suficientemente próximo do gene sdl para permitir a sua utilização em uma estratégia de seleção assistida por marcadores moleculares, possuindo, no estudo apresentado, uma eficiência aproximada de $80 \%$ na diagnose do caráter da apirenia. Adicionalmente, a validação deste marcador em populações diferentes da qual foi desenvolvido confirma o caráter de inespecificidade populacional do mesmo e amplia a possibilidade de sua utilização para seleção assisitida da ausência de sementes na videira.

A utilização do marcador SCC8 para seleção assistida da ausência de sementes é inédita em programas de melhoramento de uvas de mesa no Brasil, e a sua implementação em maior escala deverá contribuir para economia de tempo e insumos no desenvolvimento de cultivares de uvas sem sementes. Além disso, por se tratar de um marcador co-dominante, a sua utilização permite detectar genitores heterozigotos, possibilitando, assim, a seleção de genitores homozigotos para o caráter da apirenia no planejamento de cruzamentos.

\section{REFERÊNCIAS}

ADAM-BLONDON, A-F.; LAHOGUE-ESNAULT, F.; BOUQUET, A.; BOURSIQUOT, J. M.; THIS, P. Usefulness of two SCAR markers for marker-assisted selection of seedless grapevine cultivars. Vitis, Siebeldingen, v. 40, n. 3, p. 147-155, 2001.

BOUQUET, A.; DANGLOT, Y. Inheritance of seedlessness in grapevine (Vitis vinifera L.). Vitis, Siebeldingen, v. 35, n. 1, p. 35-42, 1996.

CAMARGO, U. A.; AMARAL, A. L.; OLIVEIRA, P. R. D. Uva sem sementes: uso da biotecnologia na busca de novas cultivares apirênicas. Biotecnologia Ciência e Desenvolvimento, Brasília, v. 2, n. 10, p. 108-112, 1999.

CAMARGO, U. A.; NACHTIGAL, J. C.; MAIA, J. D. G.; OLIVEIRA, P. R. D.; PROTAS, J. F.S. BRS Clara: nova cultivar de uva branca de mesa sem semente. Bento Gonçalves: Embrapa Uva e Vinho, 2003a . (Comunicado Técnico, 46).

CAMARGO, U.A.; NACHTIGAL, J. C.; MAIA, J. D. G.; OLIVEIRA, P. R. D.; PROTAS, J. F.S. BRS Linda: nova cultivar de uva branca de mesa sem semente. Bento Gonçalves: Embrapa Uva e Vinho, 2003b . (Comunicado Técnico, 46).

CAMARGO, U. A.; NACHTIGAL, J. C.; MAIA, J. D. G.; OLIVEIRA, P. R. D.; PROTAS, J. F. S. BRS Morena: nova cultivar de uva preta de mesa sem semente. Bento Gonçalves: Embrapa Uva e Vinho, 2003c . (Comunicado Técnico, 46).

LAHOGUE, F.; THIS, P.; BOUQUET, A. Identification of a codominant scar marker linked to the seedlessness character in grapevine. Theoretical and Applied Genetics, Heidelberg, v. 97, n. 5-6, p. 950959, 1998.

LEÃO, P.C.D. Principais cultivares de uvas finas de mesa. In: LEÃO, P.C.de S. (Ed.). Uva de mesa: produção: aspectos técnicos. Brasília: Embrapa Informação Tecnológica, 2001. 128p. (Frutas do Brasil, 13).

LEFORT, F.; DOUGLAS, G.C. An efficient micro-method of DNA isolation from mature leaves of four hardwood tree species Acer, Fraxinus, Prunus and Quercus. Annals of Forest Science, Versailles, v. 56, p. 259-263, 1999.

PRATT, C. Reproductive anatomy in cultivated grapes - a review. American Journal of Enology and Viticulture, Davis, v. 22, n. 2, p. 92-109, 1971. 
PROTAS, J.F.S.; CAMARGO, U.A.; MELLO, L.M R. A vitivinicultura brasileira: realidade e perspectivas. 2003. Disponível em: $<$ http:// www.cnpuv.embrapa.br/vitivini.html>. Acesso em: 10 abr. 2005.

RAGHAVA, G. P. S. Improved estimations of DNA fragment lengths from gel eletroforesis using a graphical method. 1994. Disponível em: <http://bioinformatics.uams. edu/mirror/dnasize>. Acesso em: 10 abr. 2005.
SAFRA de frutas tropicais aumenta exportações. Jornal da Fruta, Lages, v. 13, n. 165, p. 1, 2005.

STOUT, A. B. Seedlessness in grapes. New York Agriculture Experimental Station Technology Bulletin, New York, v. 238, n. 33, p. 1-65, 1936. 